\title{
开封城市水域生态系统服务价值评估及影响因素分析
}

\author{
苗赫萌 ${ }^{1,3}$, 元 媛 ${ }^{1,2}$, 李天奇 ${ }^{1,2}$, 朱悦悦 ${ }^{1}$, 焦文献 $1,2, *$ \\ 1 河南大学地理与环境学院, 开封 475004 \\ 2 黄河中下游数字地理技术教育部重点实验室 (河南大学), 开封 475004 \\ 3 河南大学民生学院, 开封 475004
}

摘要:评估城市水域生态系统服务价值是城市生态调查的重要内容。以北方水城一一开封市为研究对象,基于双边界二分式条 件价值评估法评估受访者对城市水域生态系统服务的支付意愿。然后构建包含环境感知变量的 Logistic 模型,探究支付意愿的 影响因素。结果表明: 1 $73.17 \%$ 的受访者对开封城市水域生态系统服务具有正支付意愿, 支付意愿率较高。其中男性支付率 高于女性, 文化程度越高其支付率越高, 居住于水域附近的本地居民支付率高于外地游客, 曾有过捐款经历可以提高支付率。

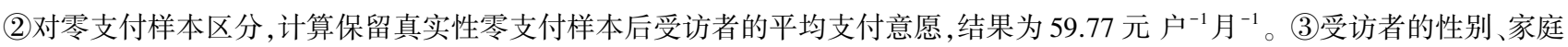
月收人、生态行为对支付意愿有显著影响。建议加强环保教育, 为公众搭建参与城市生态建设的平台, 提升公众生态行为, 有利 于提高城市水域生态系统服务价值。研究丰富了城市水域生态系统服务价值评估案例, 可以为政府部门合理引导公众参与城 市生态建设提供参考。

关键词: 城市水域; 生态系统服务; 条件价值评估法; 零支付样本; 开封市

\section{Assessment of urban waters ecosystem service value and analysis of its influencing factors in Kaifeng City}

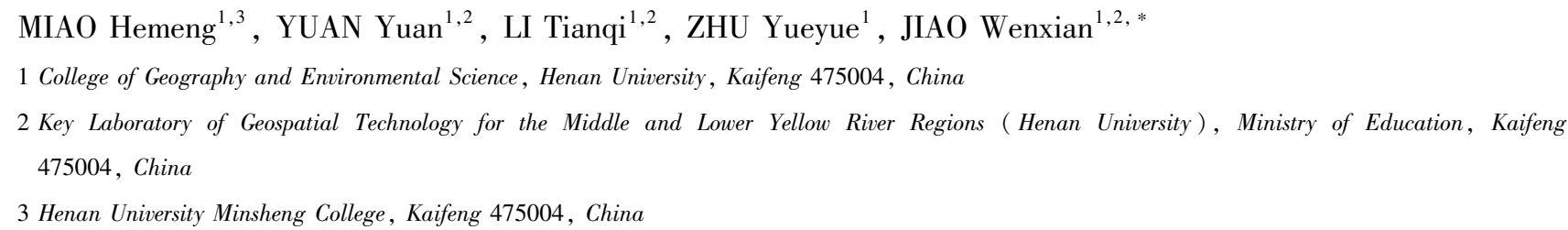

\begin{abstract}
The evaluation of urban water ecosystem service value is an important part of urban ecological survey. Taking Kaifeng City as the research object, the willingness to pay for urban water ecosystem services was evaluated based on the double-boundary dichotomy of contingent valuation method. Then we constructed a logistic model including environmental perception variables to explore the influencing factors of willingness to pay. The results showed that: (1) 73.17\% of the respondents had positive willingness to pay for the ecosystem services of Kaifeng urban waters, and the rate of willingness to pay was high. Among them, the payment rate of men was higher than that of women, and the higher the education level was, the higher the payment rate was. The payment rate of local people living near the water area was higher than that of foreign tourists, and the past donation experience can improve the payment rate. (2) Distinguishing the zero payment samples, the average willingness to pay was 59.77 yuan per household per month after retaining the authenticity of zero payment samples was calculated. (3) Gender, family monthly income and ecological behavior of the respondents had
\end{abstract}

基金项目: 国家自然科学基金项目(41601112,41771142); 河南省自然科学基金项目(202300410077,212300410126)

收稿日期: 2021-02-28; 接收日期:2021-09-28

* 通讯作者 Corresponding author.E-mail: jwx@ henu.edu.cn 
significant impact on their willingness to pay. We suggested to strengthen environmental protection education, build a platform for the public to participate in urban ecological construction, improve public ecological behavior. It is beneficial to increase the value of urban water ecosystem services. This study enriches the assessment cases of urban water ecosystem service value, and can provide scientific reference for government departments to guide the public to participate in urban ecological construction reasonably.

Key Words : urban waters; ecosystem services; Contingent Valuation Method; zero-payment sample; Kaifeng City

生态系统服务是指生态系统与生态过程所形成和维持的人类赖以生存的自然环境条件与效用 ${ }^{[1]}$ 。千年 生态系统评估指出生态系统服务包括供给、调节、文化与支持服务, 认为全球 $60 \%$ 的生态系统功能正在或已 经退化, 主要受到人类活动的干扰 ${ }^{[2]}$ 。作为生态系统的重要组成部分, 城市生态系统一方面能够提供多种生 态系统服务, 与人类生产生活密切相关, 另一方面也受到城市化带来的巨大改变,引发诸如生态破坏、环境污 染等生态问题 ${ }^{[3]}$ 。城市河流湖泊能够提供特殊的生态系统服务, 如休闲娱乐、气候调节、水质净化、改善空气 质量等 ${ }^{[4]}$, 城市水域生态质量直接影响城市居民的生活质量。在人地关系日益紧张的城市区域开展对城市 生态系统尤其是城市河流、湖泊等水域生态系统的价值评估, 有助于加深公众对城市水域生态系统服务价值 的认识,为政府部门引导公众参与城市生态建设提供参考依据,具有重要现实意义。

自 Daily ${ }^{[5]}$ 和 Costanza ${ }^{[4]}$ 开展生态系统服务研究以来,生态系统服务价值评估的研究内容和研究方法不 断丰富,迅速成为生态经济学研究前沿。国内早期的研究首先认识到不同类型生态系统服务价值存在差异, 重点评估了森林 ${ }^{[6-7]}$ 、草地 ${ }^{[8-9]}$ 、湿地 ${ }^{[10]}$ 、流域 ${ }^{[11]}$ 等生态系统服务价值,其研究方法一般基于 Constanza 的生态 系统服务分类体系, 依据单位面积土地利用类型的生态系统服务价值,进行总经济价值的核算。这种以全球 平均水平评估区域实际的方法, 缺乏对当地不同类型生态系统服务价值的测算。条件价值评估法 (Contingent Valuation Method, CVM)引人我国后,使用 CVM 评估区域水生态系统服务价值的研究案例逐渐增多,现有实 证分析的特点主要表现在两个方面。一方面是 CVM 研究的问卷格式由早期的连续型转变为离散型。学者们 首先采用支付卡式调查问卷对黑河流域张掖地区 ${ }^{[12]}$ 和额济纳旗 ${ }^{[13]}$ 的生态系统服务价值进行评估,初步核算 当地生态系统服务的总经济价值, 然后逐渐认识到受访者在支付意愿的选择上对 “同意”或 “不同意” 的回答 比直接选择最大支付意愿额度更能模拟市场的定价行为,之后开始采用连续型的开放式、支付卡式问卷和离 散型的单边界、双边界二分式问卷进行分析比较 ${ }^{[14-15]}$ 。结果表明: 采用不同类型问卷格式的评估结果有较大 差异, 离散型问卷设计更加符合市场中的议价过程, 能够有效提高评估结果的可靠性。相关研究 ${ }^{[16-17]}$ 从提高 CVM 有效性和可靠性的视角, 对单边界和双边界二分式 CVM 进行比较, 认为双边界二分式 CVM 在单边界二 分式 CVM 问卷中增加一次对受访者支付意愿的询问, 获得受访者更多关于支付意愿的信息, 因此提高了评估 结果的精度。选择合适的 CVM 问卷格式是采用 CVM 开展生态系统服务价值评估研究成功与否的关键。另 一方面是对支付意愿的影响因素进行更为深人的分析。对比部分生态价值评估的研究成果, 不同研究区域和 调查对象的支付意愿影响因素不完全相同。几乎所有研究均表明收人是影响支付意愿的重要因素, 而受访者 的其他社会经济属性如性别、年龄、文化程度、职业类型等因素对支付意愿的影响存在较大差异。杨凯对上海 浦东张家浜城市河流生态系统服务价值评估的结果表明, 受访者的收人、文化程度、捐款经历、环境态度与支 付意愿显著正相关, 家庭人口越多其支付意愿越低 ${ }^{[18]}$ 。梁勇对银川市居民改善城市水环境支付意愿的研究 结果表明, 居民的收人、文化程度、对水务部门信任程度越高, 对水环境现状满意程度越低, 其支付意愿越 高 ${ }^{[19]}$ 。在刘耀涁对南昌城市河湖生态系统价值评估的研究结果中, 不同文化程度的居民其支付意愿存在较 大差异 ${ }^{[20]}$ 。在陈红光对三江平原生态旅游水资源价值评估的研究结果中, 收人越多、文化程度越高、对水资 源保护更加关心的受访者越愿意支付,年龄越大越不愿意支付 ${ }^{[16]}$ 。上述研究主要分析受访者社会经济属性 对支付意愿的作用,较少关注社会经济属性以外的变量。此外, 部分学者在对受访者环境认知情况和支付意 
愿进行相关分析时, 缺乏对环境认知变量的分类讨论。虽然国内对城市水域生态系统服务价值的研究已逐渐 增多,但以具体城市作为研究区域的案例仍相对较少。不同类型城市的经济发展水平和生态治理能力不尽相 同,引导公众参与城市生态建设的政策和途径也需因地制宜,应当根据当地城市生态系统服务价值评估结果 进行精准指导。

开封是典型的“北方水城”,市区水域面积达 $170 \mathrm{hm}^{2}$,共有河流、湖泊等 11 处水域(图 1)。2017-2020 年 实施的“一渠六河” 水利连通工程通过新建河道、清理淤泥、拦污截污、修复生态和提升景观,构建起连接新老 城区的水系,真正将死水变活、污水变清, 同时也完善了城市水域生态系统结构,形成内外联通、相互循环的城 市水域生态系统。在此背景下, 选取开封市作为城市水域生态系统服务价值评估的研究区域具有一定代表 性。本文采用双边界二分式 CVM 调查开封市居民的支付意愿,评估城市水域生态系统服务价值。在支付意 愿的影响因素分析方面,本文除了考虑受访者的社会经济属性,还加人生态感知、生态意识、生态行为、政府公 信力评价等四类环境认知特征变量, 从而更广泛的探究支付意愿的影响因素。研究旨在通过正确评估开封城 市水域生态系统服务价值, 丰富不同类型城市水域生态系统服务价值评估的研究案例, 为政府部门合理引导 公众参与城市生态建设提供参考依据。

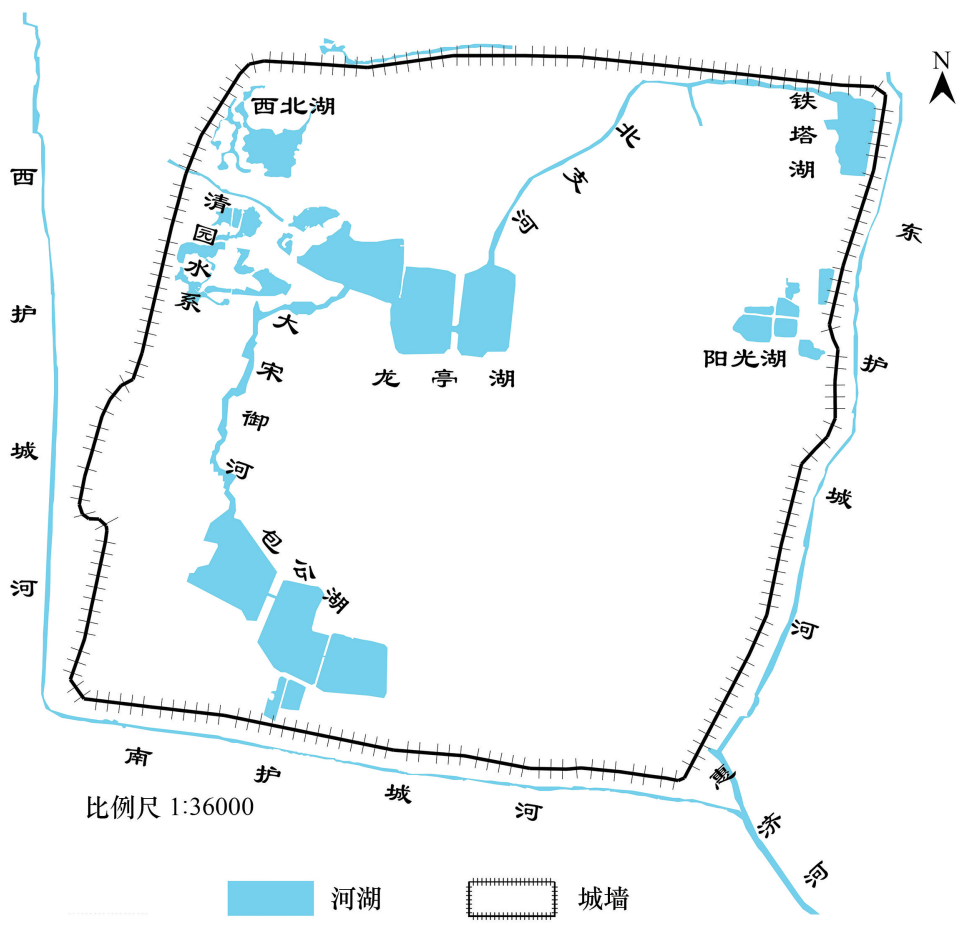

图 1 开封市老城区河湖水系示意图

Fig.1 Schematic diagram of river and lake water system in the old urban area of Kaifeng City

\section{1 研究方法与数据来源}

\section{1 研究方法}

\subsection{1 双边界二分式 CVM}

条件价值评估法是一种典型的陈述偏好评估法, 通过营造假想的市场环境, 直接询问受访者对某种生态 环境产品变化的最大支付意愿 (Willingness To Pay, WTP)或最小受偿意愿 (Willingness To Accept, WTA), 以 此来估算某种生态环境产品改善提高或恶化损失的经济价值 ${ }^{[21]}$ 。原则上 WTA 与 WTP 等价, 但在实际应用 中 WTA 可能远高于 WTP ${ }^{[22-23]}$, 所以人们更多使用真实性和稳定性较好的 $\mathrm{WTP}^{[24]}$ 估算生态产品价值。 
在 CVM 问卷调查中,如何获得 WTP 是问卷设计的核心问题。常见的 WTP 引导技术有 4 种: 开放式、支 付卡式、单边界二分式和双边界二分式。早期研究多采用开放式和支付卡式引导技术 ${ }^{[12-13]}$, 这种方法的特点 是操作方便, 无需进行复杂的数学统计。随着 CVM 研究的不断发展, WTP 引导技术逐渐向二分式转变, 尤其 是双边界二分式 CVM 得到广泛应用 ${ }^{[16-17,25]}$ 。

双边界二分式问卷的设计思路是: 在一组给定的投标值中,随机给出一个值作为初始投标值,询问受访者 是否愿意接受。如果接受,则进一步提出较高投标值询问受访者是否接受; 反之,则询问受访者对较低投标值 的回答。此时,受访者的回答有 “愿意-愿意 (yes-yes)”、“愿意-不愿意 (yes-no )”、“不愿意-愿意 ( no-yes)” 和 “不愿意-不愿意 (no-no)” 4 种情况。本文基于双边界二分式引导技术, 根据受访者的 4 种回答情况建立与投 标值之间的函数关系,估算受访者的平均最大支付意愿。

1.1.2 WTP 的计算方法及模型

根据随机效用模型, 假设环境物品从 $Q_{0}$ 改善到 $Q_{1}$, 个体获得的效用 $U$ 由可观察项 $V$ 和不可观察项 $\varepsilon$ 组 成, 个体效用 $U$ 是环境状态 $Q$ 、个体收人 $Y$ 和社会经济属性 $S$ 的函数 ${ }^{[26-29]}$ :

$$
U=V(Q, Y, S)+\varepsilon
$$

为了得到更好的环境服务, 当受访者需要支付的额度为 $T$ 时, 其接受的概率为:

$$
P(\text { yes })=P\left[U_{1}\left(Q_{1}, Y-T, S\right)-U_{0}\left(Q_{0}, Y, S\right) \geqslant 0\right]=P[\varepsilon \leqslant \Delta V]=1-G(T)
$$

式中, $\Delta V=V_{1}\left(Q_{1}, Y-T, S\right)-V_{0}\left(Q_{0}, Y, S\right)$, 表示可观察效用差, 定义 $\Delta V=\alpha-\beta T ; G$ 为受访者的 WTP 分布函数, 假定 $G$ 服从 Logistic 分布。

双边界二分式 CVM 中, 初始投标值为 $T$, 较高投标值为 $T^{U}$, 较低投标值为 $T^{L}$, 那么受访者 4 种不同回答的 概率可以表示为:

$$
\begin{aligned}
& P(\text { yes } / \text { yes })=P^{y y}=1-G\left(T^{U}\right) \\
& P(\text { yes } / \text { no })=P^{y n}=G\left(T^{U}\right)-G(T) \\
& P(\text { no } / \text { yes })=P^{n y}=G(T)-G\left(T^{L}\right) \\
& P(\text { no } / \text { no })=P^{n n}=G\left(T^{L}\right)
\end{aligned}
$$

则双边界二分式 CVM 的对数函数为:

$$
\ln L=\sum_{i=1}^{n}\left[d_{i}^{\mathrm{YY}} \ln P^{\mathrm{YY}}+d_{i}^{\mathrm{YN}} \ln P^{\mathrm{YN}}+d_{i}^{N \mathrm{~N}} \ln P^{\mathrm{NY}}+d_{i}^{\mathrm{NN}} \ln P^{\mathrm{NN}}\right]
$$

式中, $d^{\mathrm{YY}}, d^{\mathrm{YN}}, d^{\mathrm{NY}}, d^{\mathrm{NN}}$ 分别为 4 种回答对应的结果,均为虚拟变量。如果受访者的回答为“同意-同意”, 则 $d^{\mathrm{YY}}=1$, 其余情况则 $d^{\mathrm{YY}}=0$ 。同理, 对 $d^{\mathrm{YN}}, d^{\mathrm{NY}}, d^{\mathrm{NN}}$ 分别进行定义。

\subsubsection{Logistic 模型}

Logistic 回归模型采用最大似然法进行模型参数估计, 选择受访者对初始投标值是否具有支付意愿作为 因变量, 要求因变量 $Y$ 取值为 0 或 1 , 即愿意支付为 1 , 否则取值为 0 。将 $Y=1$ 的概率记为 $P$, 取其对数 $\operatorname{logit} P=\ln \left(\frac{P}{1-P}\right)$ 。假设 $x_{1}, x_{2}, \cdots, x_{m}$ 表示影响受访者支付意愿的自变量, 则 Logistic 回归模型表示为:

$$
\operatorname{logit} P=\ln \left(\frac{P}{1-P}\right)=\beta_{0}+\beta_{1} x_{1}+\beta_{2} x_{2}+\cdots+\beta_{m} x_{m}
$$

式中,参数 $\beta_{0}$ 为截距, $\beta_{j}(j=1,2, \cdots, m)$ 为回归系数。整理可得:

$$
P=\frac{\exp \left(\beta_{0}+\beta_{1} x_{1}+\beta_{2} x_{2}+\cdots+\beta_{m} x_{m}\right)}{1+\exp \left(\beta_{0}+\beta_{1} x_{1}+\beta_{2} x_{2}+\cdots+\beta_{m} x_{m}\right)} \text { 或 } 1-P=\frac{1}{1+\exp \left(\beta_{0}+\beta_{1} x_{1}+\beta_{2} x_{2}+\cdots+\beta_{m} x_{m}\right)}
$$

1.2 数据来源

\subsection{1 问卷设计}

美国国家海洋和大气管理局 (NOAA) 提出在 CVM 问卷调查前必须对调查者进行培训,进行预调查,调查 
过程采取面对面访谈的形式 ${ }^{[30]}$ 。根据 NOAA 提出的原则和国内外相关研究的经验, 预调查于 2018 年 9 月 23 日在开封部分水域附近进行。根据受访者反馈的意见,对问卷的投标范围和问题设置进行调整。正式调查问 卷主要包括以下 4 个部分:

第一部分是对开封市水域生态系统现状的描述和展望。结合正在实施的“一渠六河” 水利连通工程, 向 受访者阐述城市水域生态系统服务的重要性和具体体现, 并对未来作了展望。通过图文并茂的描述, 为受访 者模拟真实的市场环境。

第二部分是对受访者环境认知情况的调查。以往研究多关注支付意愿与受访者社会经济属性的关系, 但 相关研究表明 ${ }^{[31]}$, 环境变化感知可能影响人们的应对策略, 从而对支付意愿产生影响。因此, 本研究引人生 态感知、生态意识、生态行为和政府公信力评价等四部分内容调查受访者的环境认知情况。

第三部分是对受访者社会经济属性的调查。主要有性别、年龄、文化程度、职业类型、家庭月收人等问题。 有研究表明,近期捐款经历可显著提高受访者的支付意愿 ${ }^{[18]}$, 但鲜有研究探究其他社会经济属性对支付意愿 的作用。结合实际情况，问卷加人了对受访者常住地、是否沿水和捐款经历的调查。

第四部分是对受访者支付意愿的调查。包括采用双边界二分式引导技术的支付意愿调查以及受访者同 意或不同意支付原因的调查。在双边界二分式引导问题之后, 本研究设置了开放式问题, 结合受访者不同意 支付的原因, 可对真实性和抗议性零支付进行区分 ${ }^{[32-33]}$ 。其中核心估值问题如下:

开封城市水域生态系统环境改善工程需要大量资金,除市政投人外,可能还需要来自社会大众的支持:

(1) 您是否愿意以家庭为单位,未来 3 年内, 每月支付 元?

$\square$ 愿 意( 请转至回答第 2 题) $\square$ 不愿意 (请转至回答第 3 题)

(2) 您是否愿意以家庭为单位, 未来 3 年内, 每月支付 元( 较高值)?

$\square$ 愿 意

$\square$ 不愿意

(3) 您是否愿意以家庭为单位,未来 3 年内, 每月支付 元( 较低值)？

$\square$ 愿 意

$\square$ 不愿意

（4）如果您愿意支付的金额不在上述范围, 请填写您的真实支付意愿 元 月 $^{-1} \dot{户}^{-1}$ 。

考虑到受访者对家庭计量单位和月收人更敏感,且开封城市水域生态系统环境改善工程( “一渠六河” 水 利连通过程) 将在 3 年内 (2017-2020 年) 完工, 故本文在核心估值问题上采用每户每月的支付额度。根据敖 长林 ${ }^{[34]} 、$ Cooper ${ }^{[35]}$ 的研究和预调查的结果, 本研究确定 8 种投标值组合 (单位: 元), 分别为: $1-3-5 、 3-5-$ $10 、 5-10-20 、 10-20-30 、 20-30-50 、 30-50-100 、 50-100-200 、 100-200-300$ 。样本总数在各投标组 合中平均分配,并根据实际情况对个别组合进行数量调整。

\subsection{2 问卷调查}

开封是著名的旅游城市, 为保证本地居民在受访者中的比例, 正式调查避开节假日, 选择在 2018 年 911 月的工作日进行。综合参考谢弗抽样公式和敖长林等 ${ }^{[34]}$ 研究, 确定发放调查问卷 550 份。调查地区覆盖 开封市 11 处重点水域, 根据按比例分配原则和实际人口分布, 适当调整各区域问卷分配。此次调查全部采用 面对面问卷调查方式,剔除填写不完整和随意作答的无效问卷后, 得到有效问卷 507 份, 有效率为 $92.18 \%$ 。

\section{2 结果与分析}

\section{1 样本特征描述性统计分析}

\subsection{1 社会经济属性统计}

本文选取性别、年龄、文化程度、职业类型、常住地、居住地是否沿水、捐款经历和家庭月收人等指标作为 受访者的社会经济属性变量 (表 1)。男性比例略高于女性,约 $52: 48$, 且男性支付率高于女性, 可能与男女性 别比例和男性收人较高有关。受访者年龄主要集中在 18-50 岁之间, 占样本总量的 $91.71 \%$ 。年龄在 $18-40$ 岁之间时, 支付率随年龄增加而逐渐增大, $31-40$ 岁时支付率最高, 51 岁后支付率明显降低, 可能与受访者达 
到退休年龄从而导致收人减少有关。受访者的文化程度整体较高, $72.58 \%$ 的受访者接受过高中及以上教育, 并且随着文化程度的提高, 支付率在不断上升, 说明高学历在一定程度上能够提高受访者对模拟市场的认知 从而提高支付率。受访者的职业类型以工商、餐饮、服务业从业人员为主,占比 $78.7 \%$ 。军人、教师、学生和政 府或企事业单位人员往往拥有较高的学历和稳定的收人, 对生态环保工作更加关心, 因此支付率最高, 达 $79.45 \%$ 。根据《开封统计年鉴(2019)》 ${ }^{[36]}, 2018$ 年开封市常住人口中男性占 $51.46 \%$,女性占 $48.54 \%$, 文化程 度为小学及以下的比例占 $9.31 \%$, 初中占 $23.26 \%$, 高中/中专占 $32.56 \%$, 本科/专科及以上占 $34.88 \%$, 大体上 与本调查结果相当。由于 CVM 调查的需要, 为保证受访者对家庭情况充分了解, 本调查主要选取 18 岁以上 的受访者。其他变量如职业类型、家庭月收人均与统计年鉴提供的信息基本接近。因此,可以认为本调查样 本具有良好的代表性。

表 1 样本社会经济属性统计 $(N=507)$

Table 1 Statistics of social-economic attributes $(N=507)$

\begin{tabular}{|c|c|c|c|c|c|}
\hline $\begin{array}{l}\text { 变量 } \\
\text { Variables }\end{array}$ & $\begin{array}{l}\text { 定义 } \\
\text { Definitions }\end{array}$ & $\begin{array}{l}\text { 人数 } \\
\text { Number }\end{array}$ & $\begin{array}{l}\text { 频率/\% } \\
\text { Frequency }\end{array}$ & $\begin{array}{c}\text { 正支付率/\% } \\
\text { Positive payment rate }\end{array}$ & $\begin{array}{c}\text { 均值 } \\
\text { Mean value }\end{array}$ \\
\hline 性别 & 1:男 & 263 & 51.87 & 74.52 & 0.52 \\
\hline Gender & 0:女 & 244 & 48.13 & 71.72 & \\
\hline 年龄 & $1:$ 小于 18 岁 & 3 & 0.59 & 66.67 & 3.50 \\
\hline \multirow[t]{5}{*}{ Age } & $2: 18-30$ 岁 & 131 & 25.84 & 75.57 & \\
\hline & $3: 31-40$ 岁 & 134 & 26.43 & 80.60 & \\
\hline & $4: 41-50$ 岁 & 125 & 24.65 & 70.40 & \\
\hline & $5: 51-60$ 岁 & 75 & 14.79 & 64.00 & \\
\hline & 6 : 大于 60 岁 & 39 & 7.70 & 66.67 & \\
\hline 文化程度 & $1:$ 小学及以下 & 33 & 6.51 & 57.58 & 2.98 \\
\hline \multirow[t]{3}{*}{ Education } & 2 :初中 & 106 & 20.91 & 73.58 & \\
\hline & 3:高中/中专 & 206 & 40.63 & 72.82 & \\
\hline & 4 : 本科/专科及以上 & 162 & 31.95 & 76.54 & \\
\hline 职业类型 & $1:$ 农民 & 35 & 6.90 & 65.71 & 2.07 \\
\hline \multirow{2}{*}{ Occupation types } & 2:工商餐饮服务等 & 399 & 78.70 & 72.68 & \\
\hline & 3:军政教企事业单位 & 73 & 14.40 & 79.45 & \\
\hline 常住地 & $1:$ 本地 & 452 & 89.15 & 73.89 & 0.89 \\
\hline Locality & 0 : 外地 & 55 & 10.85 & 67.27 & \\
\hline 居住地是否沿水 & $1:$ 是 & 315 & 62.13 & 76.83 & 0.62 \\
\hline Is the residence along the river? & 0 :否 & 192 & 37.87 & 67.19 & \\
\hline 捐款经历 & 1 : 有 & 289 & 57.00 & 76.82 & 0.57 \\
\hline Donation experience & 0 :无 & 218 & 43.00 & 68.35 & \\
\hline 家庭月收人 & $1: 3$ 千元以下 & 67 & 13.21 & 65.67 & 3.18 \\
\hline \multirow[t]{7}{*}{ Monthly household income } & $2: 3$ 千一 -5 千元 & 136 & 26.82 & 72.79 & \\
\hline & $3: 5$ 千一 8 千元 & 125 & 24.65 & 80.00 & \\
\hline & $4: 8$ 千一 1 万元 & 94 & 18.54 & 72.34 & \\
\hline & $5: 1$ 万- 1.5 万元 & 34 & 6.71 & 64.71 & \\
\hline & $6: 1.5$ 万- 2 万元 & 21 & 4.14 & 76.19 & \\
\hline & $7: 2$ 万一 -5 万元 & 16 & 3.16 & 75.00 & \\
\hline & $8: 5$ 万元以上 & 14 & 2.76 & 71.43 & \\
\hline
\end{tabular}

尽管调查已经采取措施尽量避免游客参与,但仍有 $10.85 \%$ 的受访者来自外地。对比两类人群的支付率， 本地居民 $73.89 \%$ 的支付率高于外地游客。外地游客所获得生态系统服务的频率和质量远不如本地居民, 因 此支付率较低。62.13\% 的受访者居住地沿水, 其支付率为 $76.83 \%$,显著高于居住地不沿水 $67.19 \%$ 的支付率, 
说明距离河湖水域越近,受访者支付意愿越强,这与居民获得生态系统服务的方便程度和接收到的环境信息 量成正比。57\%的受访者曾有过捐款经历, 公共意识较强,对生态系统服务的公共属性更加敏感,因此其支付 率较高, 达 $76.82 \%$ 。受访者的家庭月收人集中在 3 千-1 万元之间, 占比 $70.01 \%$, 但支付率并不随收人增加 而逐渐上升,而是在 5 千一 8 千元之间达到最高。当受访者收人在 1 万一 1.5 万元之间时,其支付率甚至低于 3 千元以下的支付率, 这与邵帅等 ${ }^{[37]}$ 得出中等收人阶层环境支付意愿最大的结论相似。

\subsection{2 环境认知特征分析}

受访者的支付意愿除了受社会经济属性变量的影响外,还可能与环境认知情况有关 ${ }^{[31]}$ 。因此本调查设 计了 10 个环境认知问题,对其分类后将生态感知、生态意识、生态行为、政府公信力评价等四项指标作为受访 者的环境认知特征变量 (表 2)。根据统计数据,受访者对所在地区的水域环境评价不高, “满意” 及 “非常满 意” 的比例为 $26.23 \%$, 普遍反映存在水质混浊、河道堵塞、污染严重等问题。 $50.3 \%$ 的受访者认为水域环境近 年来在逐渐变好, 尤其是正在实施的“一渠六河” 水利连通工程对水域环境质量起到很大改善作用。94.08\% 的受访者认为“生态保护比经济发展更重要”或“生态保护与经济发展一样重要”, 说明公众的生态意识在普 遍提升, “绿水青山就是金山银山” 的生态理念深人人心。 $73.57 \%$ 的受访者认为生态环境变化对自身产生了 “很大影响”或“较大影响”,且“非常不愿意”或“不愿意”看到环境持续变差的受访者高达 $95.46 \%$, 说明公众 的生态意识很强,更加关注生态环境与自身的关系,希望得到更高质量的生态服务。

表 2 样本环境认知特征统计 $(N=507)$

Table 2 Statistics of environment cognition feature $(N=507)$

\begin{tabular}{|c|c|c|c|}
\hline $\begin{array}{l}\text { 变量 } \\
\text { Variables }\end{array}$ & $\begin{array}{l}\text { 问题 } \\
\text { Questions }\end{array}$ & $\begin{array}{l}\text { 定义 } \\
\text { Definitions }\end{array}$ & $\begin{array}{c}\text { 均值 } \\
\text { Mean value }\end{array}$ \\
\hline \multirow[t]{2}{*}{$\begin{array}{l}\text { 生态感知 }(\mathrm{EP}) \\
\text { Ecological perception }\end{array}$} & E5: 所在地区水域环境现状评价 & $\begin{array}{l}\text { 非常满意 }=5 ; \text {;满意 }=4 ; \text { 一般 }=3 ; \\
\text { 不满意 }=2 ; \text {; 非常不满意 }=1\end{array}$ & 3.34 \\
\hline & E6: 所在地区水域环境变化评价 & $\begin{array}{l}\text { 越来越好 }=5 ; \text { 基本上没变化 }=3 ; \\
\text { 越来越差 }=1\end{array}$ & \\
\hline \multirow[t]{3}{*}{$\begin{array}{l}\text { 生态意识 (EA) } \\
\text { Ecological awareness }\end{array}$} & $\begin{array}{l}\mathrm{E} 1 \text { :生态保护与经济发展哪个更 } \\
\text { 重要 }\end{array}$ & $\begin{array}{l}\text { 生态保护更重要 }=5 ; \text { 二者一样重要 }=3 ; \\
\text { 经济发展更重要 }=1\end{array}$ & 3.69 \\
\hline & $\begin{array}{l}\mathrm{E} 7 \text { :生态环境变化对您及家人生活 } \\
\text { 的影响 }\end{array}$ & $\begin{array}{l}\text { 影响很大 }=5 ; \text { 影响较大 }=3 ; \text { 影响较小 }=1 ; \\
\text { 没有影响 }=0\end{array}$ & \\
\hline & E9: 是否愿意看到环境持续变差 & $\begin{array}{l}\text { 非常不愿意 }=5 ; \text { 不愿意 }=4 \text {;无所谓 }=3 ; \\
\text { 愿意 }=2 ; \text { 非常愿意 }=1\end{array}$ & \\
\hline \multirow[t]{3}{*}{$\begin{array}{l}\text { 生态行为 }(\mathrm{EB}) \\
\text { Ecological behavior }\end{array}$} & $\mathrm{E} 2$ : 是否愿意参加环保活动 & $\begin{array}{l}\text { 非常愿意 }=5 \text {; 较为愿意 }=4 \text {; 不太愿意 }=3 \text {; } \\
\text { 不愿意 }=2 \text {; 非常不愿意 }=1\end{array}$ & 3.38 \\
\hline & E3: 是否参加过环保活动 & $\begin{array}{l}\text { 参加过很多次 }=5 ; \text { 参加过几次 }=3 ; \\
\text { 没参加过 }=1 ; \text { 不感兴趣 }=0\end{array}$ & \\
\hline & $\begin{array}{l}\mathrm{E} 4 \text { : 生产生活中是否考虑对环境的 } \\
\text { 影响 }\end{array}$ & $\begin{array}{l}\text { 考虑较多 }=5 \text {; 考虑较少 }=3 \text {; 从不考虑 }=1 ; \\
\text { 不清楚 }=0\end{array}$ & 3.55 \\
\hline \multirow[t]{2}{*}{$\begin{array}{l}\text { 政府公信力评价 (GC) } \\
\text { Evaluation of government credibility }\end{array}$} & E8: 对政府环保工作的评价 & $\begin{array}{l}\text { 帮助很大 }=5 \text {; 帮助较大 }=3 \text {; 帮助较小 }=1 ; \\
\text { 没有帮助 }=0\end{array}$ & \\
\hline & $\begin{array}{l}\text { E10: 对政府环保工作的信任度 } \\
\text { 评价 }\end{array}$ & $\begin{array}{l}\text { 非常相信 }=5 ; \text { 比较相信 }=4 ; \text { 不确定 }=3 ; \\
\text { 比较怀疑 }=2 ; \text { 非常怀疑 }=1\end{array}$ & \\
\hline
\end{tabular}

90.53\% 的受访者 “非常愿意” 或 “较为愿意” 参加环保活动, 说明公众的生态行为意愿很高, 但仅有 $45.56 \%$ 的受访者参加过环保活动, 调查中受访者普遍反映缺少闲暇时间或参与机会, 因此参加过环保活动的 受访者比例较低。此外, $53.25 \%$ 的受访者 “较多考虑” 生产生活对环境的影响, 普遍采取的措施是对生活垃圾 的正确分类和定点投放,对生活污水合理排放。74.36\%的受访者认为政府的环保工作“帮助很大” 或 “帮助较 大”, 且 $77.12 \%$ 的受访者对政府的环保工作持 “非常相信”或 “比较相信” 的态度,说明受访者对政府环保工作 的信任度较高,但对某些方面的工作评价较低,主要体现在:生态环保工程进展缓慢、影响交通出行、资金流向 不透明、信息发布不及时等。 


\section{2 平均支付意愿的计算}

对双边界二分式问卷投标值的样本分布进行分析 (表 3)，“愿意-愿意 ( Y Y Y ) ” 占比 32.54\%，“愿意-不愿 意 $(\mathrm{Y}-\mathrm{N})$ ” 占比 $19.53 \%$ ，“不愿意-愿意 $(\mathrm{N}-\mathrm{Y})$ ” 占比 $11.83 \%$ ，“不愿意-不愿意 $(\mathrm{N}-\mathrm{N})$ ” 占比 $36.1 \%$, “不愿意-不 愿意-愿意 $(\mathrm{N}-\mathrm{N}-\mathrm{Y})$ ” 的比例为 $9.27 \%$ 。其中具有正支付意愿的受访者达 $73.17 \%$,多数受访者愿意资金支持开 封城市水域生态系统环境质量改善。随着投标值的增加,受访者回答“愿意-愿意” 的比例呈减少趋势。对于 最小投标值 1 元, 其支持率为 $82.22 \%$,接近 $100 \%$ 。对于最大投标值 300 元, 其支持率为 $6.06 \%$,接近 0 。由此 判断,样本投标值的设定较好, 问卷设计较为合理。

表 3 双边界二分式问卷下投标值的样本分布 $(N=507)$

Table 3 Frequency of responses at each bid in double-bounded format $(N=507)$

\begin{tabular}{|c|c|c|c|c|c|c|c|}
\hline \multirow{2}{*}{$\begin{array}{l}\text { 投标组合/元 } \\
\text { Bid combination }\end{array}$} & \multirow{2}{*}{$\begin{array}{l}\text { Y-Y 数量/\% } \\
\text { Y-Y Number }\end{array}$} & \multirow{2}{*}{$\begin{array}{l}\mathrm{Y}-\mathrm{N} \text { 数量/\% } \\
\text { Y-N Number }\end{array}$} & \multirow{2}{*}{$\begin{array}{l}\mathrm{N}-\mathrm{Y} \text { 数量/\% } \\
\mathrm{N}-\mathrm{N} \text { Number }\end{array}$} & \multirow{2}{*}{$\begin{array}{l}\mathrm{N}-\mathrm{N}-\mathrm{Y} \text { 数量 } / \% \\
\mathrm{~N}-\mathrm{N}-\mathrm{Y} \text { Number }\end{array}$} & \multicolumn{2}{|c|}{$\mathrm{N}-\mathrm{N}-\mathrm{N} /$ 数量 N-N-N/Number/\% } & \multirow{2}{*}{$\begin{array}{l}\text { 合计 } \\
\text { Total }\end{array}$} \\
\hline & & & & & $\begin{array}{c}\text { 真实零支付 } \\
\text { Ture zero }\end{array}$ & $\begin{array}{l}\text { 抗议零支付 } \\
\text { Protest zero }\end{array}$ & \\
\hline $1-3-5$ & $30(66.67 \%)$ & $4(8.89 \%)$ & $3(6.67 \%)$ & 0 & $4(8.89 \%)$ & $4(8.89 \%)$ & $45(100 \%)$ \\
\hline $3-5-10$ & $33(57.89 \%)$ & $12(21.05 \%)$ & 0 & $4(7.02 \%)$ & 0 & $8(14.04 \%)$ & $57(100 \%)$ \\
\hline $5-10-20$ & $37(41.57 \%)$ & $23(25.84 \%)$ & $8(8.99 \%)$ & $1(1.12 \%)$ & $2(2.25 \%)$ & $18(20.22 \%)$ & $89(100 \%)$ \\
\hline $10-20-30$ & $29(34.52 \%)$ & $14(16.67 \%)$ & $14(16.67 \%)$ & $3(3.57 \%)$ & $6(7.14 \%)$ & $18(21.43 \%)$ & $84(100 \%)$ \\
\hline $20-30-50$ & $9(15.25 \%)$ & $14(23.73 \%)$ & $15(25.42 \%)$ & $4(6.78 \%)$ & $2(3.39 \%)$ & $15(25.42 \%)$ & $59(100 \%)$ \\
\hline $30-50-100$ & $20(28.17 \%)$ & $11(15.49 \%)$ & $4(5.63 \%)$ & $15(21.13 \%)$ & $7(9.86 \%)$ & $14(19.72 \%)$ & $71(100 \%)$ \\
\hline $50-100-200$ & $5(7.25 \%)$ & $16(23.19 \%)$ & $12(17.39 \%)$ & $12(17.39 \%)$ & $9(13.04 \%)$ & $15(21.74 \%)$ & $69(100 \%)$ \\
\hline $100-200-300$ & $2(6.06 \%)$ & $5(15.15 \%)$ & $4(12.12 \%)$ & $8(24.24 \%)$ & $4(12.12 \%)$ & $10(30.30 \%)$ & $33(100 \%)$ \\
\hline 合计 Total & $165(32.54 \%)$ & $99(19.53 \%)$ & $60(11.83 \%)$ & $47(9.27 \%)$ & $34(6.71 \%)$ & $102(20.12 \%)$ & $507(100 \%)$ \\
\hline
\end{tabular}

零支付问卷是指受访者拒绝支付的问卷,包含真实性零支付和抗议性零支付两种类型, 其中抗议性零支 付比例是衡量 CVM 有效性和可靠性的重要指标之一 ${ }^{[38-40]}$ 。对于零支付问卷的比例, 有研究认为合理区间是 $20 \%-35 \%{ }^{[41]}$ 。本研究中零支付问卷占样本总量的 $26.83 \%$, 虽然属于合理区间, 但大量零支付问卷的存在会 影响计算支付意愿的效度和信度,因此对其进行合理区分是有必要的 ${ }^{[38]}$ 。根据受访者“不愿意支付原因”, 可将零支付问卷区分为真实性零支付和抗议性零支付两种类型。本文参考相关研究对 “不愿意为开封城市 水域生态系统环境质量改善支付资金的原因”设计了 6 个选项：a.这是政府的责任,应该由政府买单; b. 担心 资金是否真正用于生态保护; c. 钱花了也得不到预期效果; d. 家庭收人低, 没有能力支付; e. 我不常来, 我不 是受益者; f. 对此不感兴趣。

对于真实性零支付和抗议性零支付的区分, 学界尚无定论。本文参考相关研究的判断标准 ${ }^{[32-33]}$, 认为选 项 $a 、 b 、 c$ 是抗议性零支付, 选项 $d 、 e 、 f$ 为真实性零支付。真实性零支付主要是由于受访者经济能力不足所表 现为拒绝支付, 受访者对调查对象的偏好是中性的,环境质量的好坏不影响其支付结果。抗议性零支付行为 主要来自对政府工作的不信任,因此支付意愿为 0 并非他们的真实表达结果。本调查的抗议性支付率为 $20.12 \%$,国外研究表明,抗议性支付率普遍分布在 0-15\%之间,而在发展中国家,由于公众对于环境政策了 解不充分、对政府等相关部门长期不信任等原因, 公众的抗议性支付率略高于发达国家水平 ${ }^{[42]}$ 。

国内相关研究大多将零支付问卷直接剔除 ${ }^{[20,25]}$, 仅对具有正支付意愿的样本进行计算。根据敖长林 ${ }^{[33]}$ 和袁伟 ${ }^{[42]}$ 的研究, 直接删除零支付样本会产生样本选择偏差,正确区分、处理不同类别的零支付样本可降低 调查拒绝率, 提高问卷的有效性和代表性。因此, 本研究考虑零支付样本对评估结果的影响, 将真实性零支付 样本纳人数据分析中, 根据公式 6 利用 Stata 软件对 405 个样本进行计算,得出受访者的平均支付意愿为 59.77 元 月 ${ }^{-1} 户^{-1}$ 。

2.3 支付意愿的影响因素分析

真实性零支付主要是由于受访者经济能力不足所表现为拒绝支付, 当经济实力充足时, 受访者则具有正 
支付意愿。因此在支付意愿的影响因素分析中,应当选取包含真实性零支付的样本。对含有真实性零支付的 405 个样本建立 2 个 Logistic 模型分析社会经济属性和环境认知特征对支付意愿的影响, 因变量均为受访者 的支付意愿, 分析结果见表 4 。若受访者愿意接受初始投标值, 其支付意愿赋值为 1 , 不愿意则赋值为 0 。模 型 1 的自变量是社会经济属性,模型 2 的自变量在社会经济属性的基础上加人了环境认知特征。

表 4 不同模型设定下支付意愿与影响因素的回归分析结果 $(N=405)$

Table 4 Regression analysis results of willingness to pay and influencing factors under different models $(N=405)$

\begin{tabular}{|c|c|c|c|c|c|c|c|c|}
\hline \multirow{2}{*}{$\begin{array}{l}\text { 变量 } \\
\text { Variables }\end{array}$} & \multicolumn{4}{|c|}{ 模型 1 Model 1} & \multicolumn{4}{|c|}{ 模型 2 Model 2} \\
\hline & $\begin{array}{l}\text { 系数 } \\
\text { Coef. }\end{array}$ & $\begin{array}{l}\text { 标准误差 } \\
\text { Std. Error }\end{array}$ & $Z$ & $P$ & $\begin{array}{l}\text { 系数 } \\
\text { Coef. }\end{array}$ & $\begin{array}{l}\text { 标准误差 } \\
\text { Std. Error }\end{array}$ & $Z$ & $P$ \\
\hline 常数项 Constant & -8.41 & 27.40 & -0.31 & 0.759 & -20.23 & 33.24 & -0.62 & 0.537 \\
\hline 是否本地 Local & 13.06 & 14.07 & 0.93 & 0.353 & 13.83 & 14.03 & 0.99 & 0.324 \\
\hline 是否沿水 Along & -5.70 & 9.16 & -0.63 & 0.534 & -6.28 & 9.07 & -0.69 & 0.489 \\
\hline 性别 Gender & 27.55 & 7.97 & 3.46 & 0.001 & 28.01 & 7.87 & 3.56 & 0.001 \\
\hline 年龄 Age & -3.03 & 3.49 & -0.87 & 0.385 & -3.64 & 3.53 & -1.03 & 0.302 \\
\hline 教育程度 Education & 5.03 & 5.14 & 0.98 & 0.328 & 4.40 & 5.13 & 0.86 & 0.391 \\
\hline 职业类型 Profession & 2.58 & 9.06 & 0.28 & 0.776 & 1.35 & 9.03 & 0.15 & 0.881 \\
\hline 捐款经历 Donation & 16.28 & 8.00 & 2.04 & 0.042 & 13.40 & 8.03 & 1.67 & 0.095 \\
\hline 家庭月收人 Income & 8.80 & 2.83 & 3.11 & 0.002 & 8.58 & 2.80 & 3.06 & 0.002 \\
\hline 生态感知 EP & & & & & -3.25 & 4.14 & -0.78 & 0.433 \\
\hline 生态意识 EA & & & & & -3.47 & 4.15 & -0.84 & 0.403 \\
\hline 生态行为 EB & & & & & 11.53 & 4.97 & 2.32 & 0.020 \\
\hline 政府公信力 GC & & & & & 1.02 & 4.15 & 0.24 & 0.807 \\
\hline
\end{tabular}

在模型 1 中, 性别和家庭月收人与支付意愿在 $1 \%$ 水平上显著相关, 捐款经历与支付意愿在 $5 \%$ 水平上显 著相关。男性比女性的支付意愿更大, 其支付意愿发生比是女性的 27.55 倍, 表明在本研究区域内男性受访 者更愿意支持开封城市水域生态系统质量改善,与男性支付率高于女性的结论相吻合。家庭月收人同样是显 著影响支付意愿的变量, 收人越高其支付意愿发生比就越高, 这与大多数研究结论一致。此外, 捐款经历也能 显著提高支付意愿的发生比，人们在捐款的同时会增加对受捐事物的关注，能够更加深刻的理解生态系统服 务的价值,其支付意愿也更加强烈。在其他社会经济属性变量中, 是否沿水和年龄的系数为负。距离水域越 远, 居民到达附近河湖的时间就越长, 所获得的直接生态系统服务就越少, 因此支付意愿随距离增加呈下降趋 势。随着年龄的增加, 受访者所要承担的经济压力增大, 收人大多用于生活和抚养孩子, 因此将资金投人生态 保护的意愿会逐渐降低,而且还可能与退休失去工作等因素有关。

加人受访者环境认知特征变量的模型 2 显示, 性别和家庭月收人与支付意愿在 $1 \%$ 水平上显著相关, 捐款 经历与支付意愿在 $10 \%$ 水平上显著相关,三者的系数方向和大小与模型 1 接近。说明加人环境认知特征变量 后, 在受访者的社会经济属性变量中依然是性别、家庭月收人和捐款经历能够显著影响支付意愿, 没有发生大 的改变。在环境认知特征变量方面, 生态行为与支付意愿在 $5 \%$ 水平上显著相关, 且生态行为变量每提高 1 个 单位, 支付意愿发生比就提高 11.53 倍, 表明受访者的生态行为能够显著影响支付意愿, 因此鼓励公众参与生 态环保活动、培养良好生态行为是提高支付意愿的重要举措。其他变量对支付意愿的影响较小, 说明在本案 例中受访者的生态感知、生态意识、政府公信力评价不足以影响其对生态质量改善的支付意愿。

\section{3 结论}

本研究采用模拟市场环境效果更好的双边界二分式 CVM,在开封市 11 处河流、湖泊附近发放问卷 550 份, 以此评估开封城市水域生态系统服务价值。同时, 以受访者的社会经济属性变量和环境认知特征变量为 自变量,应用二元 Logistic 回归对受访者支付意愿的影响因素进行分析。结论如下： 
(1)在 507 份有效问卷中, $73.17 \%$ 的受访者具有正支付意愿,表明多数受访者愿意支持开封城市水域生态 系统环境质量改善。但是本研究的抗议性支付率为 $20.12 \%$, 表明居民对支付生态环保费用的抗议程度较高, 主要原因是对政府环保工作缺乏信任。建议有关部门透明信息,提高办事效率,增强自身公信力。(2)居民对

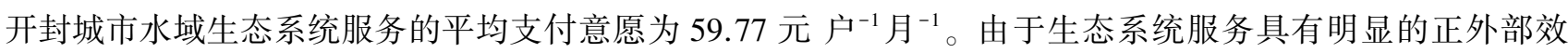
应, 这仅是对开封城市水域生态系统服务价值的粗略计算。城市水域生态系统服务价值巨大, 是促进城市生 态系统可持续发展的重要动力,应引起有关部门和社会公众的重视。3受访者的支付意愿与其性别、家庭月 收人、生态行为呈显著正相关。男性支付意愿高于女性,家庭月收人越高其支付意愿越高, 提升生态行为能够 显著提高居民的支付意愿。为提高开封城市水域生态系统服务价值, 有关部门可根据评估结果有针对性的引 导公众参与城市生态建设。

开封是著名的旅游城市,城市内部广阔的水域不仅给本地居民提供生态系统服务,还为大量游客提供休 闲娱乐支持。外地游客与本地居民对开封市水域生态系统的环境认知情况不尽相同,其社会经济属性也千差 万别, 因此探究二者的支付意愿差异和影响因素对于完善旅游地城市水域生态系统服务价值评估研究具有重 要意义。鉴于本研究中游客的样本量较小, 难以具有代表性,因此未对其进行详细讨论。计划在接下来的工 作中, 选取游客作为开封城市水域生态系统服务价值评估的研究对象, 重点探究两类人群的支付意愿差异和 影响因素的不同。

致谢: 本研究在问卷调查中得到张静珂、张璐、刘层层等同学的帮助,特此致谢。

\section{参考文献 (References) :}

［1］欧阳志云，王如松，赵景柱. 生态系统服务功能及其生态经济价值评价. 应用生态学报, 1999, 10(5): 635-639.

[ 2 ] Millennium Ecosystem Assessment. Ecosystems and Human Well-Being. Washington: Island Press, 2005.

[ 3 ] Bloom D E, Canning D, Fink G. Urbanization and the wealth of nations. Science, 2008, 319(5864) : 772- 775.

[ 4 ] Costanza R, D'Arge R, De Groot R, Farber S, Grasso M, Hannon B, Limburg K, Naeem S, O'Neill R V, Paruelo J, Raskin R G, Sutton P, Van Den Belt M. The value of the world's ecosystem services and natural capital. Nature, 1997, 387(6630) : 253-260.

[ 5 ] Daily G C. Nature's Services: Societal Dependence on Natural Ecosystems. Washington: Island Press, 1997: 49-68.

［6］赵同谦，欧阳志云，郑华，王效科，苗鸿. 中国森林生态系统服务功能及其价值评价. 自然资源学报，2004，19(4)：480-491.

[ 7 ] 肖寒, 欧阳志云, 赵景柱, 王效科. 森林生态系统服务功能及其生态经济价值评估初探一一海南岛尖峰岭热带森林为例. 应用生态学 报, 2000, 11(4): 481-484.

[ 8 ] 谢高地, 张钇锂, 鲁春霞, 郑度, 成升鬼. 中国自然草地生态系统服务价值. 自然资源学报, 2001, 16(1): 47-53.

[9] 谢高地, 鲁春霞, 肖玉, 郑度. 青藏高原高寒草地生态系统服务价值评估. 山地学报, 2003, 21(1): 50-55.

[10］吴玲玲, 陆健健, 童春富, 刘存岐. 长江口湿地生态系统服务功能价值的评估. 长江流域资源与环境, 2003, 12(5): 411-416.

[11］张志强, 徐中民, 王建，程国栋. 黑河流域生态系统服务的价值. 冰川冻土, 2001，23(4): 360-366.

［12］张志强, 徐中民, 程国栋, 苏志勇. 黑河流域张掖地区生态系统服务恢复的条件价值评估. 生态学报, 2002, 22(6): 885-893.

[13] 徐中民, 张志强, 程国栋, 苏志勇, 鲁安新, 林清, 张海涛. 额济纳旗生态系统恢复的总经济价值评估. 地理学报, 2002, 57(1)： 107-116.

[14] 张志强, 徐中民, 龙爱华, 巩增泰. 黑河流域张掖市生态系统服务恢复价值评估研究一一连续型和离散型条件价值评估方法的比较应 用. 自然资源学报, 2004, 19(2): 230-239.

[15] 徐中民, 张志强, 龙爱华, 陈东景, 巩增泰, 苏志勇, 张勃, 石惠春. 额济纳旗生态系统服务恢复价值评估方法的比较与应用. 生态学报, 2003, 23(9): 1841-1850.

[16] 陈红光, 王秋丹, 李晨洋. 支付意愿引导技术:支付卡式、单边界二分式和双边界二分式的比较一一以三江平原生态旅游水资源的非使 用价值为例. 应用生态学报, 2014, 25(9): 2709-2715.

[17] 蔡春光, 陈功, 乔晓春, 郑晓瑛. 单边界、双边界二分式条件价值评估方法的比较一以北京市空气污染对健康危害问卷调查为例. 中国 环境科学, 2007, 27(1): 39-43.

[18］杨凯，赵军. 城市河流生态系统服务的 CVM 估值及其偏差分析. 生态学报, 2005, 25(6)：1391-1396.

[19] 梁勇, 成升魁, 闵庆文, 马冬梅. 居民对改善城市水环境支付意愿的研究. 水利学报, 2005, 36(5): 613-617, 623-623. 
[20］刘耀涁, 蔡潇. 基于 CVM 的南昌城市河湖生态服务功能价值评估. 城市环境与城市生态, 2011, 24(2) : 23-26.

[21] 张志强, 徐中民, 程国栋. 条件价值评估法的发展与应用. 地球科学进展, 2003，18(3)：454-463.

[22] Brown T C, Gregory R. Why the WTA-WTP disparity matters. Ecological Economics, 1999, 28(3) : 323-335.

[23] Asafu-Adjaye J. Environmental Economics for Non-Economists. Singapore: World Scientific, 2000.

[24] 唐增, 徐中民. 条件价值评估法介绍. 开发研究, 2008, (1) : 74-77.

[25] 查爱苹, 邱洁威, 后智钢. 基于双边界二分式条件价值法的杭州西湖风景名胜区旅游资源非使用价值评估. 生态科学, 2017, 36(2)： 135- 143 .

[26] Loomis J B, Walsh R G. Recreation Economic Decisions: Comparing Benefits and Costs. 2nd ed. Pennsylvania: Venture Publishing Inc., 1997: 159- 176 .

[27] Bateman I J, Willis K G. Valuing Environmental Preferences: Theory and Practice of the Contingent Valuation Method in the US, EU, and Developing Countries. New York: Oxford University Press, 1999: 302-441.

[28] Bjornstad D J, Kahn J R. The Contingent Valuation of Environmental Resources: Methodological Issues and Research Needs. Cheltenham: Edward Elgar Publishing Limited, 1999.

[29] Hanemann W M. Welfare evaluations in contingent valuation experiments with discrete responses. American Journal of Agricultural Economics, $1984,66(3): 332-341$.

[30] Arrow K, Solow R, Portney P R, Leamer E E, Radner R, Schuman H. Report of the NOAA panel on contingent valuation. Federal Register, $1993,58(10): 4601-4644$.

[31］赵雪雁, 薛冰. 干旱区内陆河流域农户对水资源紧缺的感知及适应——以石羊河中下游为例. 地理科学, 2015, 35(12) : 1622-1630.

[32] Zhang L, Fukuda H, Liu Z H. Households' willingness to pay for green roof for mitigating heat island effects in Beijing (China). Building and Environment, 2019, 150: 13-20.

[33] 敖长林, 袁伟, 王锦茜, 高琴. 零支付对条件价值法评估结果的影响一以三江平原湿地生态保护价值为例. 干旱区资源与环境, 2019, $33(8): 42-48$

[34] 敖长林, 周领, 焦扬, 王世雪. 初始投标值数量和样本容量对双边界二分式 CVM 的影响. 生态学报, 2016, 36(3)：854-862.

[35] Cooper J C. Optimal bid selection for dichotomous choice contingent valuation surveys. Journal of Environmental Economics and Management, 1993, $24(1): 25-40$

[36] 开封市统计局. 开封统计年鉴一2018. 开封: 开封市统计局, 2019.

[37] Shao S, Tian Z H, Fan M T. Do the rich have stronger willingness to pay for environmental protection? New evidence from a survey in China. World Development, 2018, 105: 83-94.

[38] Meyerhoff J, Liebe U. Protest beliefs in contingent valuation: explaining their motivation. Ecological Economics, 2006, 57(4) : 583-594.

[39] Strazzera E, Scarpa R, Calia P, Garrod G D, Willis K G. Modelling zero values and protest responses in contingent valuation surveys. Applied Economics, 2003, 35(2): 133-138.

[40] Carson R T. Contingent valuation: a user's guide. Environmental Science \& Technology, 2000, 34(8) : 1413- 1418.

[41] Ready R C, Buzby J C, Hu D Y. Differences between continuous and discrete contingent value estimates. Land Economics, 1996, 72(3): 397-411.

[42] 袁伟. 零支付对条件价值法评估结果的影响研究 [D]. 哈尔滨: 东北农业大学, 2019. 